\title{
Visual Improvement following Continuous Positive Airway Pressure Therapy in Diabetic Subjects with Clinically Significant Macular Oedema and Obstructive Sleep Apnoea: Proof of Principle Study
}

\author{
Rebecca H. Mason ${ }^{a}$ Christine A. Kiire ${ }^{c}$ Dawn C. Groves ${ }^{c}$ Helen J. Lipinski $^{c}$ \\ Alyson Jaycock ${ }^{c}$ Barbara C. Winter ${ }^{b}$ Lewis Smith $^{c}$ Anne Bolton ${ }^{c}$ \\ Najib M. Rahman ${ }^{b}$ R. Swaminathan ${ }^{d}$ Victor N. Chong ${ }^{c} \quad$ John R. Stradling ${ }^{b}$ \\ ${ }^{a}$ Musgrove Park Hospital, Taunton, ${ }^{b}$ Oxford Centre for Respiratory Medicine, Churchill Hospital, ' Oxford Eye Hospital, \\ John Radcliffe Hospital, Oxford, and d Department of Chemical Pathology, St. Thomas' Hospital, London, UK
}

\section{Key Words \\ Obstructive sleep apnoea - Diabetes · Retinopathy • \\ Visual acuity $\cdot$ Clinically significant macular oedema}

\begin{abstract}
Background: Diabetic retinopathy and diabetic macular oedema are more prevalent in patients with coexistent obstructive sleep apnoea (OSA). Objectives: We assessed if treatment of OSA with continuous positive airway pressure (CPAP) might improve visual acuity (VA). Methods: A total of 35 patients with clinically significant macular oedema (CSMO) and OSA [oxygen desaturation index (ODI) $\geq 10$ or apnoea-hypopnoea index (AHI) $\geq 15$ ] were identified and agreed to be studied. VA (expressed as the logarithm of the minimum angle of resolution, logMAR), macular thickness, fundal photographs, glycosylated haemoglobin (HbA1c) and rhodopsin mRNA were measured twice at baseline and at 3 and 6 months post-CPAP. Fluorescein angiography and the Epworth Sleepiness Scale (ESS) were obtained once at baseline and at 6 months. Results: Three patients withdrew before the first trial visit. Thus, a total of 32 patients (17 males) entered the study, and 4 subsequently withdrew; thus 28 completed 6 months of follow-up. Baseline characteristics
\end{abstract}

of the subjects were as follows [mean (SD or inter-quartile range)]: age 66.2 (7.1) years, body mass index 31.7 (6.3), HbA1c 7.4\% (1.44) [57.1 (15.7) mmol/mol], AHI 16.5 (11-25), ODI 16.0 (12-25), ESS 6.5 (4.0-12.0) and duration of diabetes 9.5 years (5.0-16.5). Participants were divided into 13 high and 15 low CPAP compliers ( $\geq$ and $<2.5 \mathrm{~h} /$ night over the 6 months, respectively). At 6 months, the adjusted treatment effect on VA of high compliance versus low compliance was 0.11 (95\% confidence interval 0.21 to $-0.002 ; p=0.047$ ), equivalent to a one-line improvement on the logMAR chart. There was no significant improvement in macular oedema or fundal photographs. Conclusions: This hypothesis-generating, uncontrolled study suggests that $\geq 2.5 \mathrm{~h} / \mathrm{night}$ CPAP usage over 6 months in individuals with CSMO and OSA may be associated with improvement in VA. This provides justification for a randomised controlled trial of CPAP therapy in such patients.

Copyright $\odot 2011$ S. Karger AG, Basel

\section{Introduction}

Diabetic macular oedema is a common form of diabetic retinopathy. The retina thickens at the macula and this leads to a gradual loss of central vision. Clinically

\section{KARGER \\ Fax +4161306 1234 \\ E-Mail karger@karger.ch}

www.karger.com (c) 2011 S. Karger AG, Basel

0025-7931/12/0844-0275\$38.00/0

Accessible online at:

www.karger.com/res
Rebecca H. Mason

Oxford Sleep Unit, The Churchill Hospital

Old Road

Headington OX3 7LE (UK)

Tel. +44 1865225 227, E-Mail rebeccamason21@ hotmail.com 
significant macular oedema (CSMO) is defined as retinal thickening within $500 \mu \mathrm{m}$ of the fovea, hard exudates within $500 \mu \mathrm{m}$ of the fovea with adjacent retinal thickening or retinal thickening $>1,500 \mu \mathrm{m}$ in diameter within $1,500 \mu \mathrm{m}$ of the fovea [1].

Obstructive sleep apnoea (OSA) causes apnoeas or hypopnoeas, intermittent hypoxia, increased inspiratory effort, recurrent arousals and surges in sympathetic activity which lead to increases in heart rate and blood pressure (during the day, and also transiently with each apnoea), as well as fragmented sleep and daytime sleepiness. Increasingly, OSA has been associated with obesity, diurnal hypertension, insulin resistance, type II diabetes, the metabolic syndrome, endothelial dysfunction, development of atherosclerosis, aortic aneurysms and an increased risk of cardiovascular morbidity and mortality [2-11].

In a previous study by West et al. [3], 23\% of men with type II diabetes had evidence of significant OSA, as compared to an age- and body mass index (BMI)-matched population. As a consequence of the high prevalence of coexistent OSA in individuals with type II diabetes, the International Diabetes Federation has recommended that patients with diabetes should be screened for OSA [12]. West et al. [3] also showed that retinopathy was more advanced in those subjects with coexistent OSA and that this association remained after allowing for age, BMI, duration of diabetes and known hypertension. Furthermore, maculopathy was found to occur 3 times as often in patients with OSA than in those without [12]. These findings are supported by other groups who have identified similar associations between sleep-disordered breathing and a high prevalence of proliferative diabetic retinopathy [13].

We have recently shown that over $50 \%$ of individuals with diabetic macular oedema had evidence of significant OSA [14]. The mechanism by which OSA might cause or accelerate diabetic retinopathy is unclear, but it may result, for example, from the intermittent hypoxia, recurrent arousals, increased catecholamine secretion and blood pressure surges.

At present there are no data on whether individuals with type II diabetes and coexistent OSA treated with continuous positive airway pressure (CPAP) therapy might experience stabilised or improved vision. This proof of principle study was performed to investigate whether CPAP therapy might offer a novel treatment option to assist in the management of CSMO in those patients with coexistent OSA and thus justify an adequately powered randomised controlled trial.

\section{Materials and Methods}

Subjects

In a previous study, we identified 80 individuals aged over 18 years with CSMO who were on the laser database at the Oxford Eye Hospital. These individuals were screened for OSA using an ApneaLink ${ }^{\circledR}$ (ResMed, MAP Medicine Technology, Martinsried, Germany) home sleep study device. This device records a patient's nasal respiratory pressure, snoring sounds and digital oximetry during sleep. The nasal pressure signal is used to derive information on apnoeas, hypopneas [to give the apnoea-hypopnoea index (AHI), i.e. events per hour of study], snoring and flow limitation. Computer analysis of the oximetry generates an oxygen desaturation index (ODI; number of dips in $\mathrm{SaO}_{2}>4 \%$ per hour of study). Although this device does not specifically identify obstructive versus central apnoeas, the additional presence of snoring and inspiratory flow limitation would strongly support the presence of mainly obstructive events. The device has been validated as an accurate instrument with which to detect snoring, apnoea-hypopneas and oxygen desaturations $[15,16]$. Manual review was performed to ensure reliability of the data. Apnoeas were defined as cessation of airflow lasting $>10 \mathrm{~s}$, and hypopneas were defined as at least a $50 \%$ reduction in airflow for $>10 \mathrm{~s}$, associated with a $\geq 4 \%$ drop in oxygen saturation. OSA severity was quantified using both the AHI and the ODI ( $\geq 4 \%$ desaturation) per hour of study, with an accompanying finding of snoring and/or inspiratory flow limitation indicating a likely obstructive origin. Participants were identified as having OSA if they had an ODI $\geq 10$ or an $\mathrm{AHI} \geq 15$.

Participants were eligible to enter this study if they had macular oedema in at least one eye involving the fovea on optical coherence tomography (OCT) and coexistent OSA.

All study participants had previously received laser therapy for CSMO on at least one occasion. During this proof of principle study, laser therapy was not withheld as it was felt that this would be unethical. However, the use of laser therapy (given during the 3 months prior to trial entry or during the trial) was accounted for in the analysis. Patients were excluded if they had known central sleep apnoea, previous OSA and were already using CPAP, heart failure or severe respiratory compromise. The study was approved by the Oxford research ethics committee (REC No. 09/H0607/10). Written informed consent was obtained from all patients.

For the purposes of this study, analysis was performed on 54 eyes from the 28 individuals who completed 6 months of followup, with 2 individuals having 1 eye on which OCT was technically unsatisfactory [haemorrhage and severe tractional epiretinal membrane (ERM)]. All 54 eyes had a central subfield macular thickness of over $288 \mu \mathrm{m}$.

\section{Protocol}

Patients attended the Oxford Eye hospital on 6 separate occasions, i.e. 2 baseline appointments 1 week apart (pre-CPAP therapy) and 4 further appointments 1 week, 1 month, 3 months and 6 months after CPAP therapy. CPAP therapy was commenced by specialist sleep nurses from the respiratory department, using automatic CPAP devices (Autoset Spirit, ResMed, Abingdon, UK). Patients received the same follow-up as per our NHS protocol.

Each study visit comprised best corrected visual acuity (BCVA) assessment, fundal photographs, measurement of macula thickness using OCT and taking of blood samples to measure glycosyl- 
ated haemoglobin (HbA1c), cholesterol and rhodopsin mRNA. At visits 1 and 6, the participants completed an Epworth Sleepiness Scale (ESS) and had a fluorescein fundus angiogram.

\section{CPAP Compliance}

Compliance with CPAP was downloaded from the internal memory of the CPAP device at 3 and 6 months. A median split for CPAP compliance was made at 6 months ( $<$ or $\geq 2.5 \mathrm{~h} /$ night). Those individuals with CPAP compliance $<2.5 \mathrm{~h} /$ night were treated as a comparative group for the purposes of identifying differences in outcomes for those who did (high compliers) and did not (low compliers) adhere to treatment.

\section{Best Corrected Visual Acuity}

A modified Early Treatment Diabetic Retinopathy Study chart is the current gold standard for BCVA assessment in clinical trials. In this study, BCVA was measured for each individual, one eye at a time, at a distance of $4 \mathrm{~m}$ with the patient wearing their spectacles at each visit using a modified Early Treatment Diabetic Retinopathy Study chart. The same chart and room conditions were used throughout the study. The letter score is converted to a logarithm of the minimum angle of resolution (logMAR) scale. $\log$ MAR is a commonly used scale for VA. The logMAR scale converts the geometric sequence of a traditional Snellen chart to a linear scale. Positive values indicate vision loss and zero equals $6 / 6$ vision; thus, a fall in logMAR represents vision improvement. All steps between lines are equal. A change in logMAR of 0.1 equates to a one-line improvement or reduction in visual acuity (VA).

\section{Retinopathy Grading from Fundal Photography}

Fundal photography is a routine investigation to examine retinal changes, performed by trained technicians and interpreted by trained graders according to the English National screening programme protocol [17]. A routine macula image from each eye was reviewed when of sufficient quality for evidence of retinopathy (graded R0-R3). Maculopathy and photocoagulation scars were not analysed, as all study entrants were under review at the eye hospital for CSMO and had had previous laser therapy. Images were reviewed by two independent ophthalmology graders (D.C.G. and A.J.) who were blinded to CPAP compliance and severity of OSA. Where there were discrepancies between the graders, a third trained independent grader (H.J.L.) acted as arbitrator.

\section{Optical Coherence Tomography}

Eye-tracking dual-laser spectral domain OCT (Heidelberg Spectralis HRA + OCT, Heidelberg Engineering, Heidelberg, Germany) is a technique which allows sub-surface images of a translucent or opaque material to be obtained; it works as an 'optical ultrasound' but using laser, imaging reflections from within tissue to provide cross-sectional images of the retina. A small part of the retina can be measured repeatedly over time, with an interobservation difference of less than $6 \mu \mathrm{m}$. OCT allows the objective measurement of a structural effect on the macula thickness of a particular intervention.

OCT was carried out by ophthalmic photographers, and the images were interpreted by an ophthalmologist with a special interest in retinal disease. The test results in a circular contour map which is subdivided into concentric rings representing different regions. The thickness at the central point and central subfield region represents the degree of retinal thickening at the central part of the macula; this is considered to be the most reproducible output for use in clinical trials [18]. In our study, measurements of the central point and central subfield retinal thickness were used; the measurements for subsequent concentric rings were not analysed.

The OCT images were graded (V.N.C. and C.A.K.) to assess whether there appeared to be capacity for improvement in vision, based on retinal structure as identified on a contour map produced by the Spectralis OCT machine. Factors documented for this assessment were the following: (1) the external limiting membrane integrity, identified as (a) normal, (b) mildly disrupted or (c) grossly disrupted; (2) the degree of macular oedema, identified as either (a) involving the foveal pit or (b) diffuse without involving the foveal pit, and (3) the presence of an ERM, documented as (a) not present, (b) mild ERM without traction, (c) severe ERM with traction or (d) vitreomacular traction at the fovea.

\section{Fluorescein Angiography}

Fluorescein angiography (Heidelberg Spectralis HRA2, Heidelberg Engineering) is a technique for examining the circulation of the retina by injecting sodium fluorescein into the systemic circulation followed by photographing the retina after illumination with a blue light (wavelength $490 \mathrm{~nm}$ ). Fluorescein fundus angiogram pictures were used to identify changes in the foveal avascular zone, with enlargement of the foveal avascular zone suggesting worsening eye disease and vice versa. The avascular zone is quantified in screen pixels.

\section{Rhodopsin mRNA}

It has previously been shown that circulating levels of rhodopsin mRNA, corrected to $\beta$-actin mRNA levels, are higher in individuals with diabetic retinopathy [19]. Wong et al. [20] showed that circulating retina-specific $m R N A$ levels in patients with type II diabetes were higher in the presence of OSA, defined as more than five $4 \%$ oxygen desaturations per hour. This suggests that extra hypoxia may modulate the expression of genes in the retina. Blood samples were collected into PAXgene blood RNA tubes. Total RNA was extracted from the samples and reverse-transcribed into cDNA. Retina-specific rhodopsin mRNA was measured by quantitative real-time PCR, corrected for $\beta$-actin mRNA and expressed as a ratio. The change in mRNA ratio was assessed at baseline and 6 months to identify whether the effect of CPAP therapy could reduce evidence of ongoing retinal repair.

\section{Data Analysis}

All assessments were performed blinded to the degree of CPAP compliance. All values are presented as means (SD) or medians (interquartile range) when not normally distributed, unless otherwise stated. Statistical analyses were performed either with SPSS version 17 (SPSS Inc., Chicago, Ill., USA) or Stata version 9.0. Initially, a paired t test or a Mann-Whitney $U$ test was performed as appropriate to assess differences between outcomes at baseline and follow-up, in both the high compliers and low compliers separately. Next, unpaired t tests were used to compare the changes between the two groups. Finally, linear regression modelling was performed to control for differences in any factors associated with the outcomes ( $p<0.20$ considered significant in model building) and of pre hoc biological interest. The linear regression model included all subjects and determined independent predictors of the change in logMAR, OCT central subfield retinal thickness and 


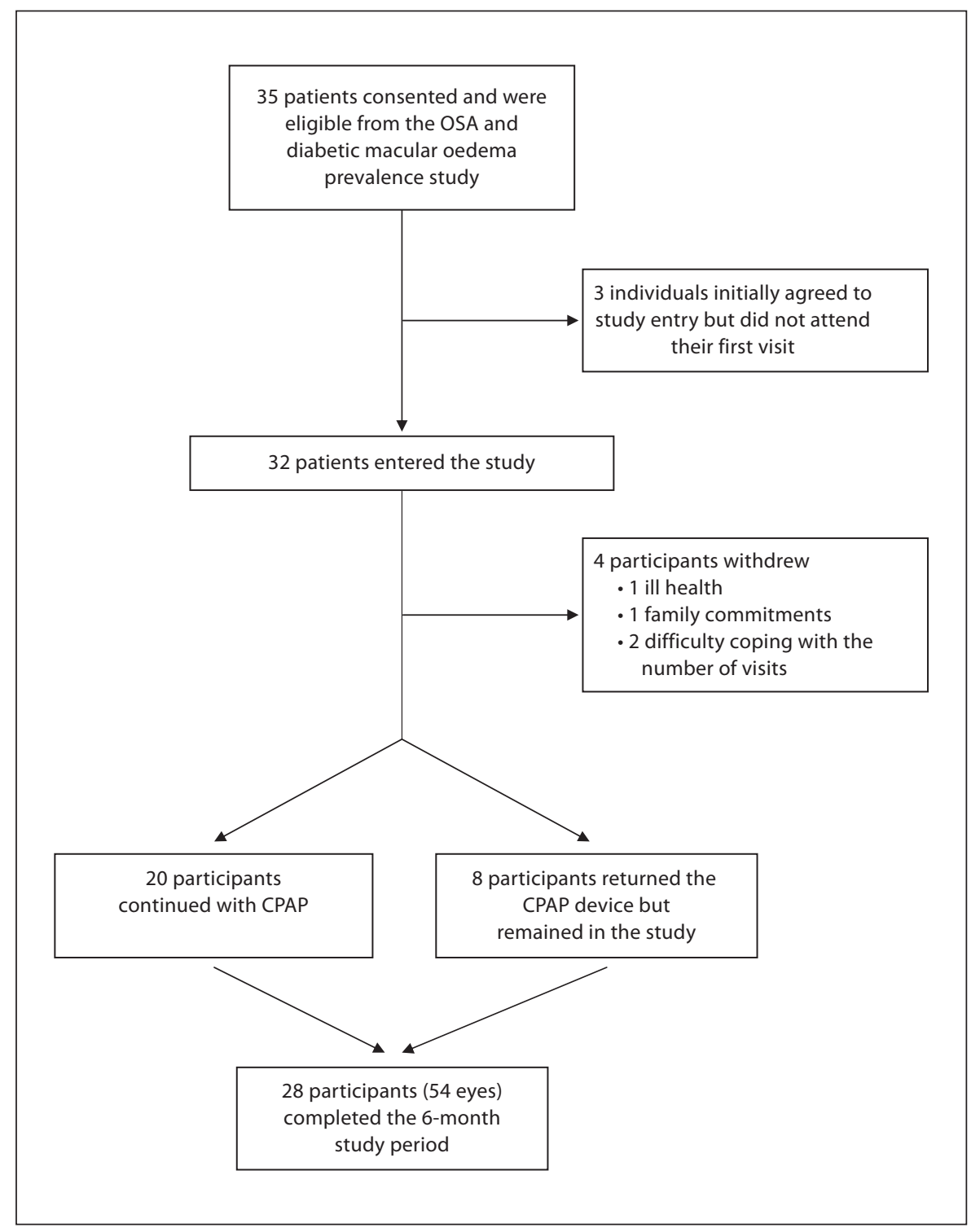

Fig. 1. Pilot study profile.

rhodopsin mRNA. This modelling provided an adjusted treatment effect between high and low compliers. Comparison of results according to the 4 grades of retinal structure and capacity for improvement was performed using one-way ANOVA. A p value of $<0.05$ was considered to be statistically significant for all tests.

\section{Results}

\section{Study Profile and Participant Characteristics}

Thirty-five out of 80 participants with type II diabetes from our original prevalence study [14] were eligible and consented to enter this proof of principle study. Three participants failed to attend their first study visit. Four subsequently withdrew, and 28 participants completed all 6 study visits. The study profile is shown in figure 1.

A comparison at baseline of those patients who did and did not subsequently comply with CPAP treatment identified no significant differences in terms of age, BMI, severity of OSA or baseline diabetes control, i.e. HbAlc (table 1). However, high compliers had a longer duration of diabetes and were more sleepy at baseline.

There was no improvement in diabetes control in either group over the course of the study as measured by 
Table 1. Baseline and 6-month change data for high compliers versus low compliers

\begin{tabular}{|c|c|c|c|c|}
\hline Number & 13 & 15 & & \\
\hline Age, years & $66.8(6.1)$ & $65.7(8.1)$ & $1.2(-4.5$ to 6.8$)$ & $0.67^{\mathrm{a}}$ \\
\hline Males/females, $\mathrm{n}$ & $11 / 6$ & $10 / 5$ & & $0.91^{\mathrm{c}}$ \\
\hline BMI & $30.3(6.3)$ & $32.9(6.2)$ & $-2.6(-7.5$ to 2.3$)$ & $0.28^{\mathrm{a}}$ \\
\hline Mean systolic BP, mm Hg & $149.6(11.1)$ & $147.9(21.3)$ & $1.7(-11.8$ to 15.2$)$ & $0.59^{\mathrm{a}}$ \\
\hline Mean diastolic BP, $\mathrm{mm} \mathrm{Hg}$ & $78.2(7.9)$ & $80.6(15.4)$ & $-2.31(-12.1$ to 7.4$)$ & $0.63^{\mathrm{a}}$ \\
\hline Duration of DM, years & $14(7-20)$ & $6(5-10)$ & & $0.003^{\mathrm{b}}$ \\
\hline Patients undergoing laser therapy, $\mathrm{n}$ & $6 / 13$ & $9 / 15$ & & $0.93^{\mathrm{c}}$ \\
\hline CPAP use, $\mathrm{h} /$ night & $5.0(1.4)$ & $0.61(0.79)$ & $4.4(3.55-5.30)$ & $<0.001^{\mathrm{a}}$ \\
\hline $100 \%$ range & $2.6-7.3$ & $0-2.14$ & & \\
\hline Baseline central subfield macular thickness, $\mu \mathrm{m}$ & $362.0(89.6)$ & $360.0(84.5)$ & $1.8(-46.3$ to 49.8$)$ & $0.94^{\mathrm{a}}$ \\
\hline Change in central subfield macular thickness, $\mu \mathrm{m}$ & $-7.56(42.3)$ & $-4.1(38.3)$ & $-3.1(-25.3$ to 19.1$)$ & $0.57^{\mathrm{a}}$ \\
\hline Baseline HbA1c, \% & $7.5(1.4)$ & $7.3(1.5)$ & $0.2(-1.0$ to 1.3$)$ & $0.74^{\mathrm{a}}$ \\
\hline Baseline $\mathrm{HbAlc}, \mathrm{mmol} / \mathrm{mol}$ & $58.2(15.4)$ & $56.2(16.5)$ & $2.0(-10.5$ to 14.4$)$ & \\
\hline Change in $\mathrm{HbA} 1 \mathrm{c}, \%$ & $0.24(0.87)$ & $-0.21(0.80)$ & $0.44(-0.20$ to 1.09$)$ & $0.17^{\mathrm{a}}$ \\
\hline Change in $\mathrm{HbAlc}, \mathrm{mmol} / \mathrm{mol}$ & $2.6(9.5)$ & $-2.3(8.7)$ & $4.90(-2.2$ to 12$)$ & \\
\hline Baseline FAZ, pixels & $1,088(679-1,571)$ & $730(477-1,576)$ & & $0.06^{\mathrm{b}}$ \\
\hline Change in FAZ, pixels & $86(-233$ to 380$)$ & $156(-195$ to 395$)$ & & $0.98^{\mathrm{b}}$ \\
\hline Baseline rhodopsin mRNA to $\beta$-actin mRNA ratio, $\times 10^{-7}$ & $6.7(1.8-141)$ & $7.0(2.2$ to 8.8$)$ & & $0.58^{\mathrm{b}}$ \\
\hline Change in rhodopsin mRNA to $\beta$-actin mRNA ratio, $\times 10^{-7}$ & $0.70(-116$ to 8.0$)$ & $0.50(-3.3$ to 4.6$)$ & & $0.66^{\mathrm{b}}$ \\
\hline \multicolumn{5}{|l|}{ Retinopathy grading } \\
\hline Baseline: R0/R1/R2/R3 & $0 / 12 / 9 / 4$ & $0 / 14 / 7 / 3$ & & $0.77^{\mathrm{c}}$ \\
\hline
\end{tabular}

Laser therapy was documented 3 months prior to study entry and during the 6-month study period. For retinopathy grading, see Materials and Methods. Values in parentheses represent SDs or interquartile ranges, as appropriate, and where not specified otherwise. $\mathrm{BP}=$ Blood pressure; $\mathrm{DM}=$ diabetes mellitus; $\mathrm{FAZ}=$ foveal avascular zone.

a t test. ${ }^{\mathrm{b}}$ Mann-Whitney $U$ test. ${ }^{\mathrm{c}} \chi^{2}$ test.

HbAlc. However, the high compliers had a significantly greater fall in ESS at 6 months.

\section{The $\log M A R$ Scale}

3-Month Data

The change in VA assessed at 3 months using a paired $\mathrm{t}$ test showed a significant improvement in both the high compliers $(\mathrm{p}=0.009)$ and low compliers $(\mathrm{p}=0.001)$. However, direct comparison of high compliers versus low compliers for logMAR change (unpaired t test) did not demonstrate a significant difference [mean difference $-0.05,95 \%$ confidence interval $(\mathrm{CI})-0.15$ to $0.05 ; \mathrm{p}=$ 0.36] (fig. 2).

Visual Improvement following CPAP in

Diabetics with Macular Oedema and OSA

\section{6-Month Data}

Change in VA assessed at 6 months using a paired t test identified a significant improvement in VA in those who complied with CPAP $(\mathrm{p}=0.016)$ and a non-significant change in those who did not $(p=0.15)$. Direct comparison of high compliers and low compliers for change in logMAR (unpaired $t$ test) demonstrated a difference between the groups of borderline significance in favour of high compliers (mean difference $-0.08,95 \% \mathrm{CI}-0.17$ to $0.01 ; \mathrm{p}=0.08$ ) (table 1; fig. 2).

For the multivariate model assessing the adjusted treatment effect of high compliance versus low compliance, analysis of potential confounders suggested that 


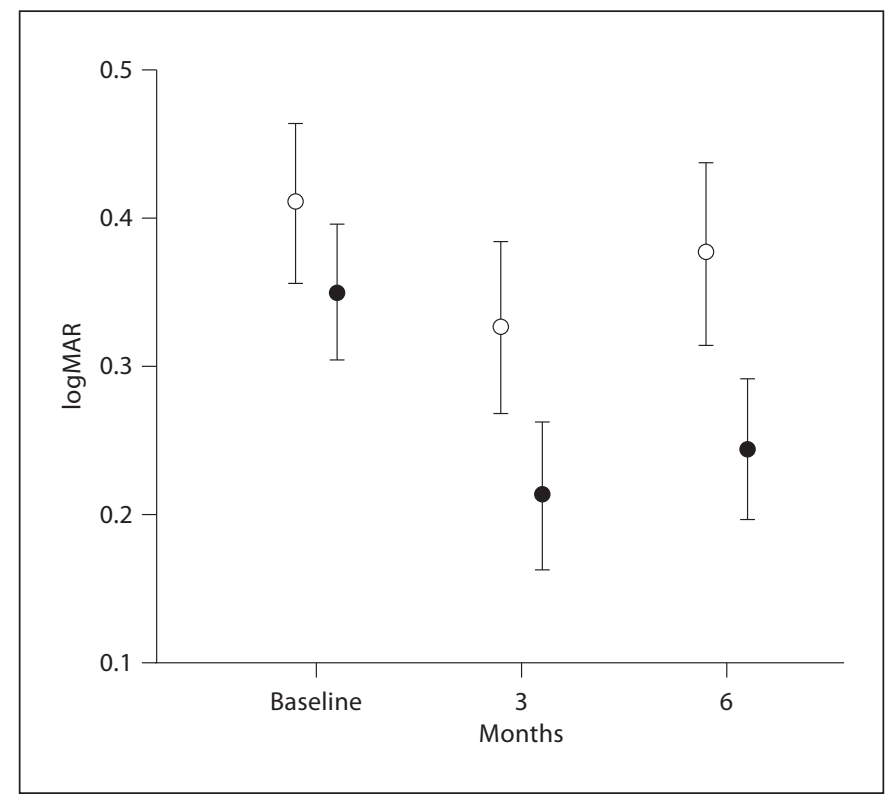

Fig. 2. VA (logMAR) after CPAP therapy in high compliers versus low compliers $(\bigcirc)$. A decrease in logMAR indicates improved vision.

only baseline cholesterol $(\mathrm{p}=0.13)$, hip size $(\mathrm{p}=0.16)$ and duration of diabetes $(\mathrm{p}=0.18)$ were sufficiently associated $(\mathrm{p}<0.2)$ with $\log$ MAR change at 6 months to be included in the model. Duration of diabetes and mean systolic blood pressure were retained in the model as factors of potential biological interest. The multivariate model, adjusting for these factors, showed that high compliance was significantly associated with $\log \mathrm{MAR}$ change at 6 months (mean change $-0.11,95 \% \mathrm{CI}-0.21$ to $-0.002 ; \mathrm{p}=$ 0.047 ) compared to low compliance. The use of laser therapy (3 months before or during the study) and change in ESS were not significantly associated with $\log$ MAR change in the multivariate model.

There was a poor correlation between logMAR change in the two eyes in individual patients, suggesting they were behaving independently, and a random effects model to account for any correlation was not materially different to the non-correlated analysis presented here. Thus, it was considered reasonable to analyse subjects' eyes independently, rather than combine the results from each eye.

\section{Central Retinal Thickness}

No statistically significant differences (all p $>0.1$ ) in central retinal thickness were identified between groups when either the central foveal point thickness or the central subfield retinal thickness was used for analysis (table 1). Neither was there a significant difference in the change in retinal thickness across the retinal structure categories ( $\mathrm{p}>0.1$, ANOVA).

\section{Retinopathy Grading from Fundal Photography}

No statistically significant differences were identified in the retinopathy severity grading ( $\mathrm{R} 0-\mathrm{R} 3)$ between the high and low compliers at baseline or follow-up (table 1).

\section{Fluorescein Fundal Angiogram}

No statistically significant difference was identified between the foveal avascular zones at baseline and followup, in either the high or low compliers (table 1).

\section{Rhodopsin mRNA}

No statistically significant differences in rhodopsin mRNA to $\beta$-actin mRNA ratios were identified between the groups, and there were no baseline variables correlated with rhodopsin mRNA to $\beta$-actin mRNA ratios (table 1).

\section{Discussion}

This is the first study to investigate the effect of CPAP for OSA in individuals with diabetic retinopathy and CSMO. Our previous work has shown a high prevalence of OSA in this patient cohort (>50\%), and the current study was designed to assess whether abolishing OSA using CPAP therapy might improve macular oedema and VA. Using a multivariate model correcting for potential confounders, high compliance with CPAP was independently associated with $\log$ MAR change at 6 months (treatment effect $-0.11,95 \% \mathrm{CI}-0.21$ to $-0.002 ; \mathrm{p}=0.047$ ) compared to low compliance. If this effect is real, it suggests that patients with OSA who comply with CPAP therapy demonstrate an average improvement in vision of 5 letters (one line on the logMAR chart). This improvement can be viewed in the context of the recently published clinical trials using anti-vascular endothelial growth factor agents, where the improvement in vision over 6 months in these studies was about 4-7 letters [2123]. The additional endpoints which attempted to identify a potential mechanism for the improvement seen in our study, which included assessment of macular thickness with OCT, the foveal avascular zone, rhodopsin mRNA and changes in retinopathy grading, did not show any significant differences. This result is perhaps 
not unexpected, as previous studies have shown that the correlation of BCVA and retinal thickness is poor [24]. However, it is possible that improvement in vision is not occurring as a result of visible structural improvements in the retina. Such improvements might, for example, be due to the fact that individuals who use CPAP become less sleepy, which may improve visual processing of the degraded visual information [median change in ESS: high compliers, -4 ( -6 to 1 ), vs. low compliers, -1 ( -3 to $0) ; \mathrm{p}=0.05]$. However, in multivariate modeling, the change in ESS was not significantly associated with the change in logMAR.

This proof of principle study has several limitations. Our findings are based on a small cohort of individuals attending the eye hospital with retinopathy severe enough to have developed CSMO. We analysed the results treating all eyes separately and thus had a considerable spread of retinopathy severity. Thus, some of the eyes may have had severe and potentially irreversible retinal changes. All our baseline OCT images were graded by graders blinded to CPAP compliance, to assess the potential for visual improvement based on retinal structure; an ANOVA identified that there was no significant difference across the groups in terms of change in logMAR over the 6 -month study period. This result suggests there may be some potential for improved vision, even at the severe end of the spectrum of retinopathy.

Laser therapy was continued throughout the study as dictated by the patients' routine ophthalmology appointments as it was felt unethical to do otherwise. It is therefore possible that ongoing laser therapy may have destroyed any potential relationship between change in VA and macular thickness. However, multiple linear regression analysis suggested that whether an eye received laser therapy or not did not influence improvement in VA ( $\mathrm{p}=$ 0.99). This result concurs with previous evidence which has identified that laser therapy acts mainly to stabilise VA rather than improve it [1]. Finally, the 6-month follow-up period may have been too short to identify changes within the foveal avascular zone and on retinal photographs.

Our findings suggest that CPAP therapy is a potentially important novel treatment for individuals with diabetic retinopathy and CSMO and coexistent OSA. However, further studies are required to accurately quantify the treatment effect, and any potential mechanism remains unclear. The retina has its highest oxygen demand at night during dark adaptation, and therefore we postulate that the added intermittent hypoxia and re-oxygenation as a result of OSA would lead to further ischaemia and damage [25]. Vascular endothelial growth factor, which is integral to normal angiogenesis, is increased during times of ischaemia and in diabetic retinopathy leads to the formation of new fragile blood vessels. The blood pressure surges which are also associated with each arousal in OSA may cause further damage to these fragile blood vessels (which lack autoregulation) and lead to increased fluid leakage and more advanced retinopathy. These blood pressure surges may also affect native blood vessels which border the macula, leading to an increase in macular oedema. Much of the work on the blood pressure surges associated with arousals in OSA has been done in populations without diabetes; the autonomic dysfunction sometimes present in those with diabetes is likely to attenuate the size of these blood pressure surges and perhaps reduce any potentially damaging effects. Finally, OSA has been shown to also raise diurnal blood pressure, which is known to be a risk factor for diabetic retinopathy $[2,26]$.

In conclusion, we have shown that individuals with OSA and clinically significant diabetic macular oedema who receive CPAP therapy and who are compliant for $\geq 2.5 \mathrm{~h}$ per night over 6 months appear to benefit from an improvement in VA at 6 months. It has not been possible to identify the mechanisms through which this effect might be taking place.

This result will need to be explored further before it can influence routine clinical practice, both with a randomised controlled trial and more detailed physiological studies to identify potential mechanisms. Using the pooled SD of the logMAR change (0.17) in this study over 6 months, and to ensure that a difference in $\log$ MAR of 0.1 between active and control treatment is not missed ( $90 \%$ power, $5 \%$ significance level), 120 subjects would need to be randomised.

\section{Financial Disclosure and Conflicts of Interest}

R.H. Mason was the recipient of an Oxfordshire Health Services Research Committee Fellowship and an unconditional grant from the ResMed Foundation. ResMed UK provided the ApneaLink devices. We would like to acknowledge the support of the National Institute for Health Research Biomedical Research Centre Oxford. 


\section{References}

1 Parravano M, Menchini F, Virgili G: Antiangiogenic therapy with anti-vascular endothelial growth factor modalities for diabetic macular oedema. Cochrane Database Syst Rev 2009;(4):CD007419.

$>2$ Pepperell JC, Ramdassingh-Dow S, Crosthwaite N, Mullins R, Jenkinson C, Stradling JR, Davies RJ: Ambulatory blood pressure after therapeutic and subtherapeutic nasal continuous positive airway pressure for obstructive sleep apnoea: a randomised parallel trial. Lancet 2002;359:204-210.

$>3$ West SD, Nicoll DJ, Stradling JR: Prevalence of obstructive sleep apnoea in men with type 2 diabetes. Thorax 2006;61:945-950.

$\checkmark 4$ Nieto FJ, Young TB, Lind BK, Shahar E, Samet JM, Redline S, D’Agostino RB, Newman AB, Lebowitz MD, Pickering TG: Association of sleep-disordered breathing, sleep apnea, and hypertension in a large community-based study. Sleep Heart Health Study. JAMA 2000;283:1829-1836.

$\checkmark 5$ Punjabi NM, Sorkin JD, Katzel LI, Goldberg AP, Schwartz AR, Smith PL: Sleep-disordered breathing and insulin resistance in middle-aged and overweight men. Am J Respir Crit Care Med 2002;165:677-682.

$>6$ Meslier N, Gagnadoux F, Giraud P, Person C, Ouksel H, Urban T, Racineux JL: Impaired glucose-insulin metabolism in males with obstructive sleep apnoea syndrome. Eur Respir J 2003;22:156-160.

7 Coughlin SR, Mawdsley L, Mugarza JA, Calverley PM, Wilding JP: Obstructive sleep apnoea is independently associated with an increased prevalence of metabolic syndrome. Eur Heart J 2004;25:735-741.

-8 Marin JM, Carrizo SJ, Vicente E, Agusti AG: Long-term cardiovascular outcomes in men with obstructive sleep apnoea-hypopnoea with or without treatment with continuous positive airway pressure: an observational study. Lancet 2005;365:1046-1053.

$\checkmark 9$ Mason RH, Ruegg G, Perkins J, Hardinge M, Amann-Vesti B, Senn O, Stradling JR, Kohler $\mathrm{M}$ : Obstructive sleep apnea in patients with abdominal aortic aneurysms: highly prevalent and associated with aneurysm expansion. Am J Respir Crit Care Med 2011;183: 668-674.
10 Büchner NJ, Quack I, Woznowski M, Stähle C, Wenzel U, Rump LC: Microvascular endothelial dysfunction in obstructive sleep apnea is caused by oxidative stress and improved by continuous positive airway pressure therapy. Respiration 2011;82:409-417.

11 Lavie L, Polotsky V: Cardiovascular aspects in obstructive sleep apnea syndrome - molecular issues, hypoxia and cytokine profiles. Respiration 2009;78:361-370.

12 Idris I, Hall AP, O’Reilly J, Barnett A, Allen M, Andrews R, Grunstein P, Lewis K, Goenka N, Wilding JP: Obstructive sleep apnoea in patients with type 2 diabetes: aetiology and implications for clinical care. Diabetes Obes Metab 2009;11:733-741.

13 Shiba T, Sato Y, Takahashi M: Relationship between proliferative diabetic retinopathy and sleep-disordered breathing (in Japanese). Nippon Ganka Gakkai Zasshi 2007; 111:899-904.

14 Mason RH, West SD, Chong V, Stradling JR: Sleep apnoea in 58 patients with diabetic macular oedema. Thorax 2010;64:A13.

15 Erman MK, Stewart D, Einhorn D, Gordon N, Casal E: Validation of the ApneaLink for the screening of sleep apnea: a novel and simple single-channel recording device. J Clin Sleep Med 2007;3:387-392.

16 Chen H, Lowe AA, Bai Y, Hamilton P, Fleetham JA, Almeida FR: Evaluation of a portable recording device (ApneaLink) for case selection of obstructive sleep apnea. Sleep Breath 2009;13:213-219.

17 Harding S, Greenwood R, Aldington S, Gibson J, Owens D, Taylor R, Kohner E, Scanlon P, Leese G: Grading and disease management in national screening for diabetic retinopathy in England and Wales. Diabet Med 2003;20:965-971.

18 Krzystolik MG, Strauber SF, Aiello LP, Beck RW, Berger BB, Bressler NM, Browning DJ, Chambers RB, Danis RP, Davis MD, Glassman AR, Gonzalez VH, Greenberg PB, Gross JG, Kim JE, Kollman C: Reproducibility of macular thickness and volume using Zeiss optical coherence tomography in patients with diabetic macular edema. Ophthalmology 2007;114:1520-1525.

-19 Hamaoui K, Butt A, Powrie J, Swaminathan $\mathrm{R}$ : Concentration of circulating rhodopsin mRNA in diabetic retinopathy. Clin Chem 2004;50:2152-2155.
20 Wong A, Merritt S, Butt AN, Williams A, Swaminathan R: Effect of hypoxia on circulating levels of retina-specific messenger RNA in type 2 diabetes mellitus. Ann NY Acad Sci 2008; 1137:243-252.

21 Massin P, Bandello F, Garweg JG, Hansen LL, Harding SP, Larsen M, Mitchell P, Sharp D, Wolf-Schnurrbusch UE, Gekkieva M, Weichselberger A, Wolf S: Safety and efficacy of ranibizumab in diabetic macular edema (RESOLVE Study): a 12-month, randomized, controlled, double-masked, multicenter phase II study. Diabetes Care 2010;33: 2399-2405.

22 Nguyen QD, Shah SM, Khwaja AA, Channa R, Hatef E, Do DV, Boyer D, Heier JS, Abraham $\mathrm{P}$, Thach AB, Lit ES, Foster BS, Kruger E, Dugel P, Chang T, Das A, Ciulla TA, Pollack JS, Lim JI, Eliott D, Campochiaro PA: Two-year outcomes of the ranibizumab for edema of the mAcula in diabetes (READ-2) study. Ophthalmology 2010;117:2146-2151.

23 Elman MJ, Aiello LP, Beck RW, Bressler NM, Bressler SB, Edwards AR, Ferris FL III, Friedman SM, Glassman AR, Miller KM, Scott IU, Stockdale CR, Sun JK: Randomized trial evaluating ranibizumab plus prompt or deferred laser or triamcinolone plus prompt laser for diabetic macular edema. Ophthalmology 2010;117:1064-1077.

24 Browning DJ, Glassman AR, Aiello LP, Beck RW, Brown DM, Fong DS, Bressler NM, Danis RP, Kinyoun JL, Nguyen QD, Bhavsar AR, Gottlieb J, Pieramici DJ, Rauser ME, Apte RS, Lim JI, Miskala PH: Relationship between optical coherence tomographymeasured central retinal thickness and visual acuity in diabetic macular edema. Ophthalmology 2007;114:525-536.

25 Arden GB, Sidman RL, Arap W, Schlingemann RO: Spare the rod and spoil the eye. $\mathrm{Br}$ J Ophthalmol 2005;89:764-769.

26 Kohler M, Pepperell JC, Casadei B, Craig S, Crosthwaite N, Stradling JR, Davies RJ: CPAP and measures of cardiovascular risk in males with OSAS. Eur Respir J 2008;32: 1488-1496. 